\title{
Concepções de Avaliação da Aprendizagem no Ensino de Ciências pela Pedagogia de Projetos: uma revisão sistemática de produções científicas do período de 2013 a 2017
}

\author{
Conceptions of learning assessment in science teaching by Project Pedagogy: \\ a systematic review of scientific productions in the period from 2013 to 2017
}

Concepciones de la evaluación del aprendizaje en la enseñanza de las ciencias a través de la pedagogía de proyectos: una revisión sistemática de las producciones científicas de 2013 a 2017

\author{
Carla Vargas Bozzato, (carlavargasbozzato@gmail.com) \\ Universidade Federal do Rio Grande do Sul - UFRGS \\ Renan Almeida Barbosa, (renanabh38@gmail.com) \\ Universidade Federal do Rio Grande do Sul - UFRGS \\ Lígia Beatriz Goulart, (ligiabeatrizgoulart@gmail.com) \\ Universidade Federal do Rio Grande do Sul - UFRGS \\ Rosane Nunes Garcia, (rosane.garcia@ufrgs.br) \\ Universidade Federal do Rio Grande do Sul - UFRGS
}

Resumo: O presente artigo investiga as concepções a respeito da avaliação da aprendizagem que permeiam produções científicas relacionadas ao Ensino de Ciências da Natureza por meio da Pedagogia de Projetos (PP), na Educação Básica. Trata-se de um estudo bibliográfico que realiza uma Revisão Sistemática de Literatura de teses e dissertações nos bancos de dados da CAPES e LUME, no período de 2013 a 2017, que resultou em dez (10) pesquisas selecionadas. A avaliação das aprendizagens na PP é apontada como uma prática pedagógica processual que precisa ser repensada em uma perspectiva formativa, rompendo com a concepção classificatória, no sentido de promover a aprendizagem. Assim, requer a adoção de estratégias e instrumentos de avaliação diversificados, que possibilitem o acompanhamento constante, o diagnóstico e a participação ativa dos sujeitos envolvidos, bem como fornecer elementos para o redirecionamento do ensino para uma prática inclusiva, que esteja a serviço da efetivação das aprendizagens.

Palavras-chave: Concepções de Avaliação da Aprendizagem; Práticas Avaliativas; Pedagogia de Projetos; Ensino de Ciências da Natureza.

Abstract: This article investigates the conceptions regarding the evaluation of learning that permeate scientific productions related to the Teaching of Natural Sciences through the 
Pedagogy of Projects (PP), in Basic Education. This is a bibliographic study that performs a systematic literature review of theses and dissertations in the CAPES and LUME databases, from 2013 to 2017, which resulted in ten (10) selected researches. The assessment of learning in PP is seen as a procedural pedagogical practice that needs to be rethought in a formative perspective, breaking with the classificatory concept to promote learning. Thus, it requires the adoption of diversified assessment strategies and instruments, which enable the constant monitoring, diagnosis, and active participation of the subjects involved, as well as providing elements for redirecting teaching towards an inclusive practice, which is at the service of implementing the learnings.

Keyword: Conceptions of Learning Assessment; Evaluative Practices; Project Pedagogy; Teaching of Natural Sciences.

Resumen: Este artículo investiga las concepciones sobre la evaluación de aprendizajes que permean las producciones científicas relacionadas con la Enseñanza de las Ciencias Naturales a través de la Pedagogía de Proyectos (PP), en Educación Básica. Se trata de un estudio bibliográfico que realiza una Revisión Literaria Sistemática de tesis y disertaciones en las bases de datos CAPES y LUME, de 2013 a 2017, que resultó en diez (10) investigaciones seleccionadas. La evaluación de aprendizajes en PP se apunta como una práctica pedagógica procedimental que necesita ser repensada en una perspectiva formativa, rompiendo con el concepto clasificatorio, con el fin de promover el aprendizaje. Así, requiere la adopción de estrategias e instrumentos de evaluación diversificados, que permitan el seguimiento, diagnóstico y participación activa constante de los sujetos involucrados, además de brindar elementos para reorientación de la docencia hacia una práctica inclusiva que esté al servicio de un aprendizaje efectivo.

Palabras clave: Concepciones de evaluación del aprendizaje; Prácticas evaluativas; Proyecto de Pedagogía; Docencia de Ciencias Naturales.

\section{INTRODUÇÃO}

Os desafios que as escolas têm enfrentado atualmente constituem terreno fértil para que educadores e pesquisadores busquem alternativas no sentido de atender as inquietações que os envolvem, como por exemplo: “O que realmente é aprender? O que é interessante aprender? Qual o tipo de ensino que desperta motivação, interesse e promove aprendizagens?’.

Em pleno século XXI são essas e outras inquietações que mobilizam inúmeras pesquisas no campo educacional. Pensando nesse contexto atual, pontua-se que o ensinar não pode se restringir apenas ao transmitir conhecimentos, "mas, antes de tudo, provocar interesses e dúvidas, fazer com que brotem questões e desenvolver métodos de pesquisa, de 
filtragem e seleção de dados, de ordenação de conteúdos, de construção da argumentação" (MOSÉ, 2013, p.13).

Vivemos em um período conhecido como a Sociedade do Conhecimento (SCHAFF, 1995) caracterizada pela grande evolução das tecnologias de informação e do surgimento de novas realidades e linguagens digitais e virtuais. Para atuarem nesse contexto, frequentemente são exigidos dos sujeitos atributos diversos tais como, por exemplo, capacidade comunicativa, domínio de diferentes, senso investigativo, criatividade, poder de argumentação e autonomia.

Nesse sentido, é importante que as escolas possam articular propostas pedagógicas que desenvolvam esses atributos, promovendo uma visão mais integrada do mundo e ultrapassando o que é geralmente imposto pelo ensino fragmentado em áreas do conhecimento ao propor situações didáticas que superem a visão parcial e limitada da realidade.

A Pedagogia de Projetos (PP $)^{1}$ surge como uma concepção de ensino sugerida em documentos oficiais, por exemplo, para atender as demandas e intencionalidades de propostas pedagógicas que envolvem mudanças nas matrizes curriculares na Educação Básica. $O$ objetivo das mudanças reside em melhorar a qualidade do ensino, através da transversalidade e da interdisciplinaridade, permitindo ao estudante articular os conhecimentos entre as diferentes áreas.

Por sua vez, essa concepção de ensino possibilita ao professor propor ações que privilegiem a pesquisa, a utilização de diversas fontes de informação e de espaços educativos, além de favorecer o desenvolvimento de habilidades para o trabalho individual e/ou coletivo. Mas, para que a PP possa atender a essa construção, requerem-se mudanças nas concepções dos professores e na realização do trabalho docente, principalmente em relação à avaliação das aprendizagens dos estudantes.

Buscando contribuir com as reflexões relacionadas à temática da avaliação e que corroboraram para qualificar e delinear uma pesquisa de doutorado $^{2}$, realizamos esta

\footnotetext{
${ }^{1}$ Por se tratar de um termo central e frequentemente usado ao longo do presente texto, optamos por utilizar a sigla PP nas próximas citações.

6. A pesquisa de doutorado que foi realizada junto ao Programa de Pós Graduação em Ensino de Ciências: Química da Vida e da Saúde, no Departamento de Bioquímica, da Universidade Federal do Rio Grande do Sul,
} 
investigação com o objetivo de identificar e analisar nas produções científicas de pesquisas educacionais, no período de 2013 a 2017, as concepções de avaliação da aprendizagem que permeiam o Ensino de Ciências da Natureza por meio da PP.

A escolha desse período coincide com a implantação da proposta pedagógica para o Ensino Médio Politécnico no estado do RS em 2011, que vigorou de 2012 a 2015, constituindo um marco histórico para muitas escolas públicas estaduais de Educação Básica que até então não trabalhavam na perspectiva de PP e gerando produção acadêmica nos diferentes campos do conhecimento.

No transcorrer desse artigo, no primeiro momento, é abordada a avaliação da aprendizagem e a PP para inserir o leitor no contexto da temática desse estudo. Na sequência, são descritos o caminho metodológico e os resultados encontrados a partir da busca realizada para evidenciar as concepções de avaliação da aprendizagem. E, por fim a análise e a discussão dos dados extraídos dessas pesquisas selecionadas, dialogando com referenciais teóricos.

\section{A AVALIAÇÃO DAS APRENDIZAGENS NA PEDAGOGIA DE PROJETOS:} REINVENTANDO OS PROCESSOS DE ENSINO E DE APRENDIZAGEM

A necessidade de superar o ensino tradicional é manifestada através dos tempos por meio de diversos movimentos, principalmente, os que se configuraram a partir do século XX. Destacamos, por exemplo, os movimentos e pesquisas que conduziram a repensar o ensino e a renovação da escola conhecido por Escola Nova (Europa, América e Brasil), tendo como expoente teórico o pedagogo John Dewey (1852-1959); ainda, os trabalhos da União da República Socialista Soviética liderados por um grupo de educadores sobre os fundamentos da escola do trabalho evidenciando Mosey M. Pistrak (1888-1940) e o artigo The project method de William Heard Kilpatrick (1918).

Esses e outros referenciais serviram para fundamentar a PP, pois neles a intencionalidade era de que a escola deixasse de ser apenas local de transmissão de conhecimentos para propor uma educação interligada aos processos de vida real e ao contexto dos sujeitos, não se restringindo em apenas uma preparação para o futuro. Essas

que investigou como as diferentes concepções de avaliação dialogam com o ensino por meio de Projetos e como essas concepções se articulam com o trabalho docente. 
intencionalidades ainda podem ser identificadas nos dias atuais em propostas pedagógicas dos sistemas de ensino do país, no sentido de mobilizar as escolas para que mudanças na educação possam ser concretizadas.

Propomos, para esse estudo, reflexões com base em algumas contribuições de autores da área educacional sobre ensinar na concepção de PP como Fernando Hernández e Montserrat Ventura (1998), Ulisses F. Araujo (2004) e Maria Teresa Esteban (2012), entre outros, para fundamentar o objeto de estudo dessa pesquisa.

Segundo Araujo (2014), a educação precisa ser reinventada sugerindo que as escolas desenvolvam projetos interdisciplinares para acompanhar as transformações ocorridas e vividas pela sociedade no contexto atual. O autor enfatiza que através dos Projetos, os educadores propõem:

[...] situações de aprendizagem dinâmicas e investigativas, capazes de envolver alunos e comunidade escolar, não somente na produção de informações, mas também no desenvolvimento de habilidades, na mudança de comportamentos e na obtenção de conhecimentos significativos de forma cooperativa, integrada e criativa (ARAUJO, 2014, p.08).

Hernández e Ventura (1998) usam o conceito Projetos de Trabalho e definem que não se trata de uma metodologia, mas sim de uma concepção de ensino e uma maneira diferente de levar os estudantes a compreensão de conhecimentos que circulam fora da escola e como caminho para a construção de sua própria identidade. Ainda, os autores expressam que essa concepção de ensino requer mudanças na maneira de exercer a docência e "um assumir o risco que implica adotar uma inovação que traz consigo, sobretudo, uma mudança de atitude profissional” (HERNANDEZ; VENTURA, 1998, p.11).

Segundo Esteban (2012, p.83), a PP estimula trabalhar com "atividades mais dinâmicas na relação ensino-aprendizagem" e "cooperativas baseadas no diálogo" em que todos envolvidos, isto é, educadores e estudantes interagem num "processo permanente de construção de conhecimentos".

Trabalhar na perspectiva da PP potencializa uma pedagogia diferenciada levando a escola a repensar seu papel, assim como, também, cabendo aos educadores rever suas concepções a respeito do ensinar, do aprender e de como avaliar as aprendizagens.

Nessa perspectiva, a avaliação das aprendizagens, segundo Esteban (2012), não pode ser confundida com a possibilidade de medir a quantidade de conhecimentos dos estudantes, tão pouco a utilização de procedimentos e instrumentos de avalição para comparar o desempenho 
com resultados previstos que se aproximam dos objetivos formulados no planejamento de ensino, gerando uma medida traduzida em nota ou conceito e favorecendo a hierarquia escolar ao oferecer elementos para a classificação desses sujeitos.

Perrenoud (1999, p.11) também associa a avaliação realizada cotidianamente nas escolas à criação de hierarquias de excelência, onde os estudantes são comparados e depois classificados conforme normas de excelência que são externas às realidades de cada um e do seu contexto.

Portanto, trilhar o campo da avaliação da aprendizagem dentro da PP remete a um caminho repleto de tensões, conflitos e contradições pelo fato de que as escolas de Educação Básica, de acordo com Lüdke (2012, p.69), recentemente têm se apropriado da "noção de Projetos como recurso de trabalho" em busca da aprendizagem com significado. Entretanto, as escolas vivem pressionadas pela busca de resultados das avaliações externas e indicadores educacionais, induzindo processos avaliativos excludentes e classificatórios.

Segundo Esteban (2012), a adoção de uma avaliação numa perspectiva classificatória, como tradicionalmente é realizada na maioria das escolas, no contexto da PP, propicia práticas contraditórias uma vez que essa concepção pedagógica implica na compreensão de que o processo da aprendizagem ocorre por meio de um "ato dinâmico, compartilhado, múltiplo e processual” (ESTEBAN 2012, p.88). A avaliação classificatória, portanto, parte de uma "concepção mecanicista de aprendizagem que valoriza as capacidades de armazenamento e de reprodução do que foi ensinado" (p.88).

Ainda segundo essa autora (2012, p.91), a PP:

[...] trabalha na perspectiva do movimento e da diferença, portanto, a avaliação precisa estar conectada ao permanente movimento de construção de conhecimentos, aqui traduzido pela ideia de "ainda não saber", que estimula o diálogo e o encontro das diferenças. A palavra "ainda" marca, no processo, a possibilidade, a continuidade, o movimento, o devir. A palavra "ainda" ressalta, na aprendizagem, sua potencialidade, sua dinâmica, permitindo que a relação pedagógica enriquecida pela heterogeneidade. A palavra "ainda" alimenta o processo de investigação.

A PP, ao propiciar uma relação pedagógica enriquecida pela heterogeneidade (ESTEBAN, 2012), tenderá para multiplicidade de instrumentos mediadores e formas diversificadas de seu uso, de acordo com as concepções do educador. Os instrumentos mediadores para avaliar as aprendizagens não devem possuir escala de poder ou eficácia, pois seu uso está articulado à compreensão do sujeito sobre as atividades nas quais são 
empregados, a organização da ação mental e da atividade interativa, não devendo ser postos numa escala em que recebam valores diferenciados. Assim, se impõe um olhar qualitativo para os percursos das aprendizagens dos alunos, bem como a adoção de novas abordagens e instrumentos avaliativos.

\section{DESCREVENDO O CAMINHO METODOLÓGICO}

O caminho metodológico nessa investigação foi a pesquisa bibliográfica (GIL, 2002) com objetivos exploratórios, buscando as concepções de avaliação da aprendizagem no Ensino de Ciências da Natureza por meio da PP, na Educação Básica, que permeiam produções científicas no período de 2013 a 2017. As fontes de busca foram os repositórios do LUME $^{3}$ - acervo digital de Teses e Dissertações defendidas no âmbito da Pós-Graduação da Universidade Federal do Rio Grande do Sul (UFRGS) e, do repositório ${ }^{4}$ disponível no site da Coordenação de Aperfeiçoamento de Pessoal do Ensino Superior (CAPES), vinculado ao Ministério da Educação (MEC). A escolha dessas plataformas digitais reside no fato que reúnem um grande acervo de produções científicas que se encaixam nas exigências das pesquisas acadêmicas.

Segundo Gil (2002, p.44), a "pesquisa bibliográfica é desenvolvida com base em material já elaborado, constituído principalmente de livros e artigos científicos", como também pode se restringir a fontes bibliográficas. O método utilizado foi a Revisão Sistemática da Literatura (RSL), que se caracteriza como uma síntese de evidências e é muito utilizada em pesquisas da área da saúde. Atualmente, outras áreas do conhecimento, como a educação, estão adotando este método pelo fato de produzir estudos a partir de uma análise confiável e rigorosa. Segundo Kitchenham (2004, p.06), a "revisão sistemática da literatura é definida como uma forma de identificação, avaliação e interpretação de trabalhos que são relevantes para uma determinada questão de pesquisa”.

A questão de pesquisa que norteou a RSL foi: "Que concepções de avaliação da aprendizagem estão presentes em produções científicas dos repositórios LUME - UFRGS e

\footnotetext{
${ }^{3}$ LUME. Repositório Digital. Universidade Federal do Rio Grande do Sul. Teses e Dissertações. Disponível em: https://lume.ufrgs.br/handle/10183/1.

${ }^{4}$ CAPES. Coordenação de aperfeiçoamento de Pessoal de Nível Superior. Ministério da Educação. Catálogo de Teses \& Dissertações. Disponível em: https://catalogodeteses.capes.gov.br/catalogo-teses/\#!/ e Portal de Periódicos. Disponível em: http://www.periodicos.capes.gov.br/.
} 
CAPES - MEC, no período de 2013 a 2017, envolvendo educadores da Educação Básica que trabalham com a PP, no Ensino de Ciências da Natureza?".

Justifica-se a escolha do período pelo fato de que a partir de 2012 as escolas públicas estaduais do RS começaram a trabalhar como o Ensino Médio Politécnico que contemplava a PP em um componente curricular denominado de Seminário Integrado e, portanto, gerou produção acadêmica nos diferentes campos do conhecimento.

A busca ocorreu a partir dos seguintes descritores: "Avaliação da Aprendizagem", "Ensino de Ciências", "Pedagogia de Projetos" e "concepções dos professores". O único descritor utilizado de forma isolada foi "Avaliação da Aprendizagem” e, posteriormente, mantido fixo para combinação com os demais por meio do comando and.

Todas as produções científicas selecionadas constituíram o corpus da pesquisa e foi utilizado como método a análise de conteúdo (BARDIN, 2016). As principais categorias foram criadas a posteriori a partir de critérios semânticos e compreenderam seis distintos agrupamentos: 1) avaliação formativa; 2) avaliação tradicional; 3) promoção da aprendizagem, 4) mudanças de concepções; 5) reorientação das práticas pedagógicas; e 6) avaliação da aprendizagem nos projetos. Para cada uma das seis categorias, foram estruturadas subcategorias de análise. As categorias com suas respectivas subcategorias estão representadas na Tabela 1 .

Tabela 1 - Categorias e subcategorias referentes às concepções de avaliação da aprendizagem usadas na análise das produções científicas dos repositórios LUME e CAPES no período de 2013 a 2017.

\begin{tabular}{|c|c|}
\hline Categorias & Subcategorias \\
\hline 1. Avaliação formativa & $\begin{array}{l}\text { - Contínua } \\
\text { - Dialógica e Reflexiva } \\
\text { - Diferenciada } \\
\text { - Superação da concepção classificatória } \\
\text { - Oferece subsídios para compreensão do processo de aprendizagem } \\
\text { - Participativa }\end{array}$ \\
\hline 2. Avaliação tradicional & $\begin{array}{l}\text { - Avaliação de desempenho } \\
\text { - Classificatória } \\
\text { - Verificar a aprendizagem } \\
\text { - Instrumentos de verificação pontual } \\
\text { - Dicotomia: seleção x aprendizagem }\end{array}$ \\
\hline 3. Promoção da Aprendizagem & $\begin{array}{l}\text { - Construção de espaços de aprendizagem } \\
\text { - Processo de construção do conhecimento } \\
\text { - Identificar as limitações e os avanços dos alunos }\end{array}$ \\
\hline \multirow[t]{2}{*}{$\begin{array}{l}\text { 4. Mudanças de concepções de } \\
\text { avaliação }\end{array}$} & $\begin{array}{l}\text { - Utilização de estratégias construtivistas } \\
\text { - Reflexão crítica } \\
\text { - Conhecimento e ação } \\
\text { - Propostas impregnadas das concepções dos professores }\end{array}$ \\
\hline & - Mudanças no ensino \\
\hline
\end{tabular}




\begin{tabular}{|l|l|}
\hline 5. Reorientação das práticas & - Postura crítica e reflexiva \\
pedagógicas & - Oportunidade de ajustes no planejamento \\
\hline 6. Avaliação da aprendizagem nos & - Mudanças na forma de avaliar \\
projetos & - Influencia nas relações dentro da escola \\
& - Viabiliza a proposta de ensino na escola \\
\hline
\end{tabular}

Fonte: elaboração dos autores, 2020.

\section{RESULTADOS DA PESQUISA}

Na biblioteca digital do LUME - UFRGS foram encontradas 3060 pesquisas com o descritor “Avaliação da Aprendizagem”. Em relação à combinação dos descritores, foram encontrados os seguintes registros de pesquisas: a) "Avaliação da Aprendizagem" and "Ensino de Ciências": 2419; b) "Avaliação da aprendizagem" and "Ensino de Ciências" and "Pedagogia de Projetos": 1303; c) "Avaliação da Aprendizagem" and "Ensino de Ciências" and "Concepções de Professores": 1659; d) "Avaliação da Aprendizagem" and "Ensino de Ciências" and "Pedagogias Projetos" and "Concepções de Professores": 1087 pesquisas. No repositório da CAPES - MEC foi encontrado um número muito maior de teses e dissertações (Tabela 2).

Tabela 2 - Números de Dissertações e Teses encontrados pela busca no Repositório da CAPES - MEC no período de 2013 a 2017.

\begin{tabular}{|l|c|c|c|}
\hline \multicolumn{1}{|c|}{ Descritores } & $\begin{array}{c}\text { Total de pesquisas } \\
\text { encontradas }\end{array}$ & Dissertações & Teses \\
\hline $\begin{array}{l}\text { "Avaliação da Aprendizagem" } \\
\text { "Avaliação da Aprendizagem" and } \\
\text { "Ensino de Ciências" }\end{array}$ & 2732.965 & 239.031 & 93.934 \\
\hline $\begin{array}{l}\text { "Avaliação da Aprendizagem" and } \\
\text { "Ensino de Ciências" and } \\
\text { "Concepções de Professores" }\end{array}$ & 379.614 & 195.615 & 94.795 \\
\hline $\begin{array}{l}\text { "Avaliação da Aprendizagem" and } \\
\text { "Ensino de Ciências" and } \\
\text { "Pedagogia de Projetos" }\end{array}$ & 336.533 & 241.768 & 94.802 \\
\hline $\begin{array}{l}\text { "Avaliação da Aprendizagem" and } \\
\text { "Ensino de Ciências" and } \\
\text { "Pedagogia de Projetos" and } \\
\text { "Concepções de Professores" }\end{array}$ & 336.534 & 241.738 & 94.795 \\
\hline
\end{tabular}

Fonte: Elaboração dos autores, 2020.

Nos processos de seleção e análise crítica, observou-se que a maioria das pesquisas discutiam temáticas que apenas tangenciavam os temas de concepções dos professores sobre avaliação da aprendizagem no Ensino de Ciências por meio da PP. A maioria das pesquisas não teve como foco o Ensino de Ciências direcionado para as séries finais do Ensino 
Fundamental ou para os componentes curriculares da área de Ciências da Natureza no Ensino Médio, ou ainda não envolviam a Educação Básica em escolas públicas e a PP. Percebemos que não existem muitas pesquisas que envolvem essa temática, pois encontramos apenas duas (2), levando a adotar outros critérios como aquelas investigações que utilizavam estratégias que conduzissem a repensar as práticas avaliativas como portfólios, ensino pela pesquisa, mapas conceituais e auto avaliação, ou que evidenciasse as concepções dos educadores sobre a avaliação da aprendizagem na área de Ciências da Natureza.

Os resultados das pesquisas selecionadas foram organizados na Tabela 3, conforme os seguintes descritores: cinco (5) com os descritores "Avaliação da Aprendizagem" and "Ensino de Ciências"; três (3) com os descritores "Avaliação da Aprendizagem" and "Ensino de Ciências" and "Concepções de Professores"; e, duas (2) apenas com os descritores "Avaliação da Aprendizagem" and "Ensino de Ciências" and "Pedagogia de Projetos" and "concepções de professores".

Tabela 3 - Identificação e caracterização das pesquisas selecionadas, conforme os descritores adotados na investigação.

\begin{tabular}{|c|c|c|c|c|c|}
\hline Descritores & Título & $\begin{array}{c}\text { Base } \\
\text { de } \\
\text { Dados }\end{array}$ & $\begin{array}{l}\text { Autoria e } \\
\text { Ano de } \\
\text { Publicação }\end{array}$ & IES & Estado/Região \\
\hline \multirow{5}{*}{$\begin{array}{l}\text { "Avaliação da } \\
\text { Aprendizagem" } \\
\text { and "Ensino de } \\
\text { Ciências" }\end{array}$} & $\begin{array}{l}\text { 1. Portfólio: uma opção de } \\
\text { avaliação integrada para o Ensino } \\
\text { de Ciências }\end{array}$ & CAPES & $\begin{array}{l}\text { Nascimento e } \\
\text { Rôças (2015) }\end{array}$ & IFRJ & RJ/Sudeste \\
\hline & $\begin{array}{l}\text { 2. Proposta de avaliação formativa } \\
\text { aplicando a aprendizagem baseada } \\
\text { em problemas (ABP) no Ensino } \\
\text { Médio }\end{array}$ & CAPES & Silva (2017) & USP & SP/Sudeste \\
\hline & $\begin{array}{l}\text { 3. Avaliação: uma proposta de } \\
\text { orientação da aprendizagem do } \\
\text { aluno e reorientação da prática } \\
\text { pedagógica do professor }\end{array}$ & CAPES & $\begin{array}{c}\text { Azevedo } \\
(2016)\end{array}$ & UFPEL & $\mathrm{RS} / \mathrm{Sul}$ \\
\hline & $\begin{array}{l}\text { 4. Avaliação da aprendizagem com } \\
\text { uso de mapas conceituais. }\end{array}$ & CAPES & $\begin{array}{l}\text { Lima et al. } \\
\text { (2017) }\end{array}$ & IFCE & CE/Nordeste \\
\hline & $\begin{array}{l}\text { 5. O compromisso formativo na } \\
\text { Avaliação da Aprendizagem em } \\
\text { Química. }\end{array}$ & CAPES & $\begin{array}{c}\text { Galvão e } \\
\text { Souza }(2016)\end{array}$ & UEL & $\mathrm{PR} / \mathrm{Sul}$ \\
\hline \multirow{3}{*}{$\begin{array}{l}\text { "Avaliação da } \\
\text { Aprendizagem" } \\
\text { and "Ensino de } \\
\text { Ciências" and } \\
\text { "Concepções dos } \\
\text { professores" }\end{array}$} & $\begin{array}{l}\text { 6. Avaliação da Aprendizagem na } \\
\text { concepção de professores de } \\
\text { Química do Ensino Médio. }\end{array}$ & CAPES & $\begin{array}{c}\text { Lemos e Sá } \\
\text { (2013) }\end{array}$ & UFSCar & SP/Sudeste \\
\hline & $\begin{array}{l}\text { 7. Avaliação da Aprendizagem na } \\
\text { escola organizada em ciclos: } \\
\text { concepções dos professores. }\end{array}$ & CAPES & $\begin{array}{c}\text { Lara e } \\
\text { Brandalise } \\
(2016) \\
\end{array}$ & UEPG & $\mathrm{PR} / \mathrm{Sul}$ \\
\hline & $\begin{array}{l}\text { 8. Concepções de um grupo de } \\
\text { professores de Ciências da } \\
\text { Natureza e suas Tecnologias sobre }\end{array}$ & LUME & $\begin{array}{c}\text { Martins } \\
(2016)\end{array}$ & UFRGS & RS/Sul \\
\hline
\end{tabular}




\begin{tabular}{|c|c|c|c|c|c|}
\hline & $\begin{array}{l}\text { o ensino por pesquisa e sobre } \\
\text { avaliação aplicada a essa } \\
\text { perspectiva de ensino: encontros e } \\
\text { desencontros em torno dessa } \\
\text { práxis. }\end{array}$ & & & & \\
\hline \multirow{2}{*}{$\begin{array}{l}\text { "Avaliação da } \\
\text { Aprendizagem" } \\
\text { and "Ensino de } \\
\text { Ciências" and } \\
\text { "Pedagogia de } \\
\text { Projetos" and } \\
\text { "Concepções dos } \\
\text { Professores" }\end{array}$} & $\begin{array}{l}\text { 9. Avaliação no ensino de ciências: } \\
\text { estudo da implantação da } \\
\text { pedagogia de projetos em escola } \\
\text { pública de ensino }\end{array}$ & CAPES & $\begin{array}{c}\text { Prasniski } \\
(2015)\end{array}$ & PUCRS & $\mathrm{RS} / \mathrm{Sul}$ \\
\hline & $\begin{array}{l}\text { 10. Avaliação no ensino de } \\
\text { ciências no nível fundamental: } \\
\text { investigando orientações oficiais e } \\
\text { práticas docentes, fazendo "escuta" } \\
\text { e pequenas intervenções em } \\
\text { escolas. }\end{array}$ & $\begin{array}{c}\text { CAPES } \\
\text { e } \\
\text { LUME }\end{array}$ & $\begin{array}{l}\text { Dantas } \\
(2017)\end{array}$ & UFRGS & RS/Sul \\
\hline
\end{tabular}

Fonte: Elaboração dos autores, 2020.

As concepções presentes nas produções científicas selecionadas em torno do foco desta pesquisa conduzem a um aporte teórico atrelado a concepções construtivistas. A perspectiva da avaliação da aprendizagem em desempenhar a função de avaliação formativa está presente em todas as pesquisas, sendo considerada como uma prática pedagógica contínua, dialógica, reflexiva, diferenciada e processual, com o objetivo de superar a perspectiva de uma avaliação tradicional e classificatória.

O Gráfico 1 mostra o número de excertos identificados nos quais essas concepções sobre avaliação formativa estão presentes nas produções científicas selecionadas e foram classificadas de acordo com as categorias estabelecidas.

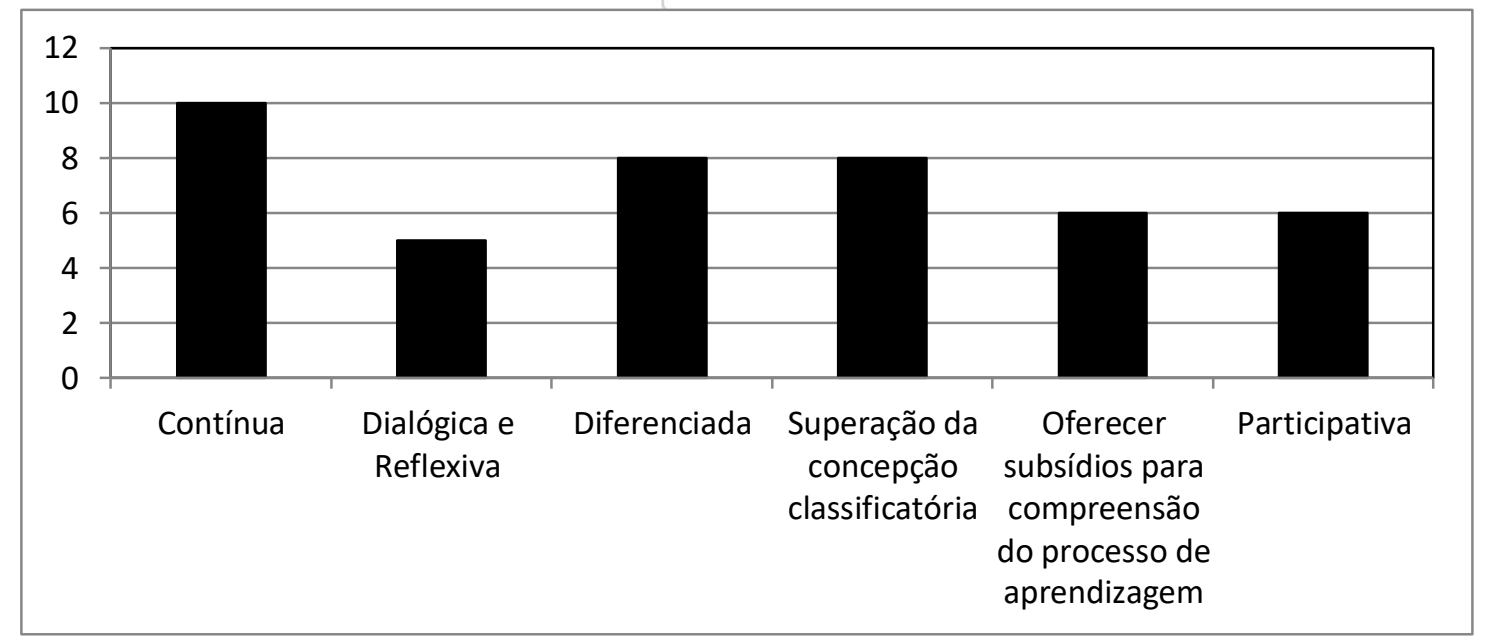

Gráfico 1- Número de Excertos presentes nas produções selecionadas que foram classificados nas Subcategorias da categoria "Avaliação formativa". 
Alguns excertos extraídos das produções 1 e 3 remetem, por exemplo, a essas concepções.

\begin{abstract}
“[...] compreende a concepção construtivista da avaliação que deve ser dialógica, mediadora, formativa e integrada ao processo ensino-aprendizagem (NASCIMENTO; RÔÇAS, 2015, p.16).

[...] a importância de o aluno ser avaliado de forma contínua, ou seja, ao longo de todo o processo de escolarização, como forma de acompanhamento de sua aprendizagem (AZEVEDO, 2016, p.23).
\end{abstract}

Mas, na maioria das pesquisas selecionadas, é sugerido que, para a superação da avaliação em uma perspectiva classificatória, os educadores precisam promover um ensino ativo, isto é, que envolva a participação colaborativa e a utilização de estratégias que incentivem o estudante a tomar inciativa, decisões, resolver problemas e refletir sobre seu processo de aprendizagem. A avaliação é parte do processo de ensino e de aprendizagem como fio condutor para essa construção. Nesse sentido, as pesquisas 1, 2, 4, 8, 9 e 10 evidenciam algumas estratégias construtivistas como, por exemplo, portfólio, mapas conceituais, ensino por pesquisa, aprendizagem baseada em problemas e Projetos.

Segundo os autores dessas pesquisas, o educador que utiliza essas estratégias é conduzido a um caminho de reflexão sobre os processos de aprendizagem, do ensino, do planejamento e da avaliação. Portanto, oferecem subsídios para compreender que a avaliação nesse contexto não deve se limitar apenas a verificação do desempenho. Essas impressões são representadas no seguinte excerto da produção 5:

[...] a utilização de mapas e redes conceituais como ferramentas de avaliação no ensino de Química. Consoante o pesquisador, a estratégia é muito significativa para o processo de ensino-aprendizagem e avaliação, pois permite verificarem-se as relações que se estabelecem entre os conhecimentos prévios e os novos, bem como entre os diferentes conceitos químicos. Os resultados revelaram-se positivos no concernente à produção de mudanças nos procedimentos avaliativos comumente utilizados em sala de aula, visto que possibilitaram maior interação entre aluno/aluno e professor/aluno, favorecendo a aprendizagem. (GALVÃO; SOUZA, 2016, p.385).

A pesquisa 2 faz referência a avaliação formativa como sendo a ideal para avaliar as aprendizagens quando o educador utiliza metodologias ativas, isto é, estratégias que se aproximam de concepções construtivistas. Tal intencionalidade está presente no seguinte excerto: "A avaliação formativa foi proposta para proporcionar o redirecionamento 
individualizado e envolver a subjetividade do professor em virtude da utilização de um tipo de metodologia ativa [...]" (SILVA, 2017).

Entretanto, o educador precisa encontrar apoio dos seus pares para não estar solitário ao propor práticas avaliativas na perspectiva de avaliação formativa. Além disso, também é importante a participação do educando, como é evidenciado nas pesquisas 2, 3, 4, 5, 9 e 10. Nesse sentido, Perrenoud (1999) diz que "o principal instrumento de toda avaliação formativa é o professor comprometido em uma interação com o aluno" (ibid., p. 81).

Na categoria Avaliação tradicional foi possível identificar excertos correspondentes às suas subcategorias cuja prática é criticada nas pesquisas por ser considerada pontual e classificatória. Entretanto, é um modelo que persiste nos contextos escolares como sendo a ideal para verificar o desempenho. O Gráfico 2 apresenta o número de excertos identificados nas produções científicas investigadas e que reportam a essas concepções.

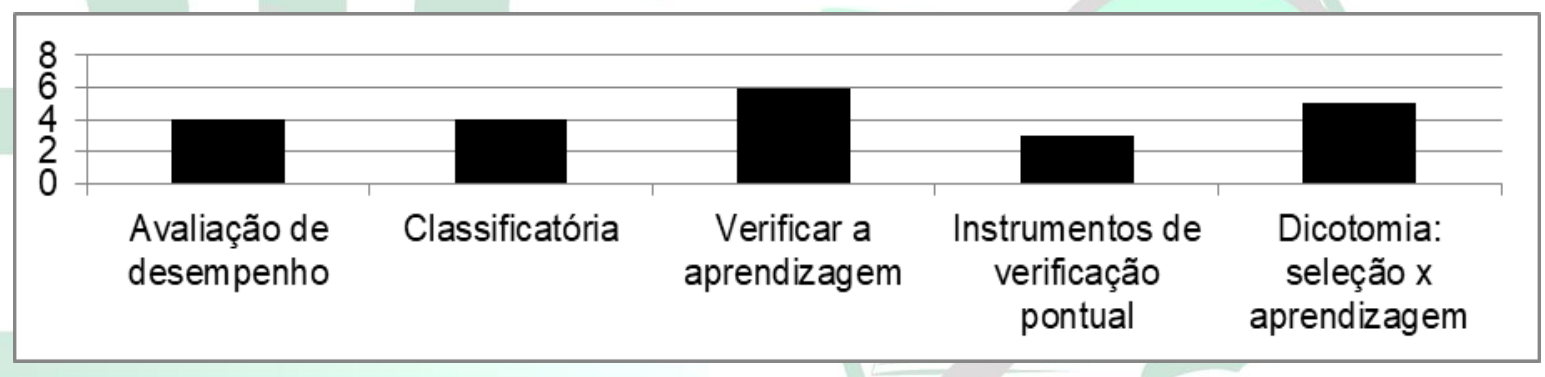

Gráfico 2 - Número de excertos presentes nas produções selecionadas que foram classificados nas subcategorias da categoria "Avalição tradicional".

Essas impressões, por exemplo, estão presentes nos seguintes excertos das produções 2, 5 e 10:

[...] o modelo de avaliação na maioria das escolas públicas, é baseado no processo classificatório, ou seja, tendo como princípio a exclusão e não a inclusão (SILVA, 2017, p.23).

Em uma perspectiva mais diretiva e tradicional, a ação avaliativa está impregnada de atributos orientados pela tríade transmissão/assimilação/reprodução, direcionando para a prática de exames [...] (GALVÃO; SOUZA, N.A., 2016, p.383).

Paradoxalmente, resistem na escola práticas de seleção e classificação dos estudantes, por meio da produção de hierarquias de excelências que são iniciadas pela disciplinarização e que se traduzem no uso da prova (DANTAS, 2017, p.09).

Através das pesquisas selecionadas, surge o entendimento de que o modelo de avaliação tradicionalmente utilizado nas escolas está atrelado à forma do educador conceber o ensino, particularmente em se tratando dos componentes curriculares da área das Ciências da 
Natureza como, por exemplo, presente no excerto da produção científica 5: "Superar a concepção de ensino-aprendizagem voltada para a transmissão/ assimilação ainda constitui um grande nó entre aqueles a ministrarem a disciplina, refletindo diretamente na avaliação da aprendizagem" (GALVÃO; SOUZA, 2016, p.381).

Em algumas pesquisas, percebe-se que o discurso de uma avaliação por desempenho é fortalecido em virtude das avaliações externas, tais como o ENEM ou das formas de avaliação para ingresso no mercado de trabalho, como é evidenciado no excerto abaixo extraído da pesquisa 1:

[...] a dicotomia "discurso-prática" muito presente na avaliação do desempenho dos alunos e, ao mesmo tempo, mostraram que todo o processo avaliativo escolar não está imune às influências das avaliações externas no país e dos sistemas educacionais nas demais esferas. As formas de colocação no mercado de trabalho por meio de avaliações em concursos e afins também inserem o processo avaliativo nas escolas submetido a forte clima de competição, fazendo parecer ao aluno e professor que os instrumentos tradicionais de avaliação são indispensáveis no processo educativo (NASCIMENTO; ROÇAS, 2015, p.24).

Nesse sentido, a compreensão da avaliação tradicional está atrelada a avaliação de desempenho e a verificação da aprendizagem para atingir objetivos específicos. Para essa construção, as pesquisas fazem menção à prova como um dos principais instrumentos avaliativos, sugerindo que os resultados fortalecem a dicotomia entre seleção x aprendizagem.

As pesquisas fortalecem o discurso da avaliação formativa atrelada à promoção da aprendizagem, pelo fato de que todas as ações articuladas levam a aprendizagem do educando. Segundo Perrenoud (1999), a concepção de avaliação formativa é considerada como sendo a mais adequada para a promoção das aprendizagens, bem como para contribuir com a melhoria e mobilização de práticas educativas e a regulação das mesmas. O gráfico 3 mostra a frequência dos excertos classificados nas subcategorias que emergem da categoria promoção da aprendizagem. 


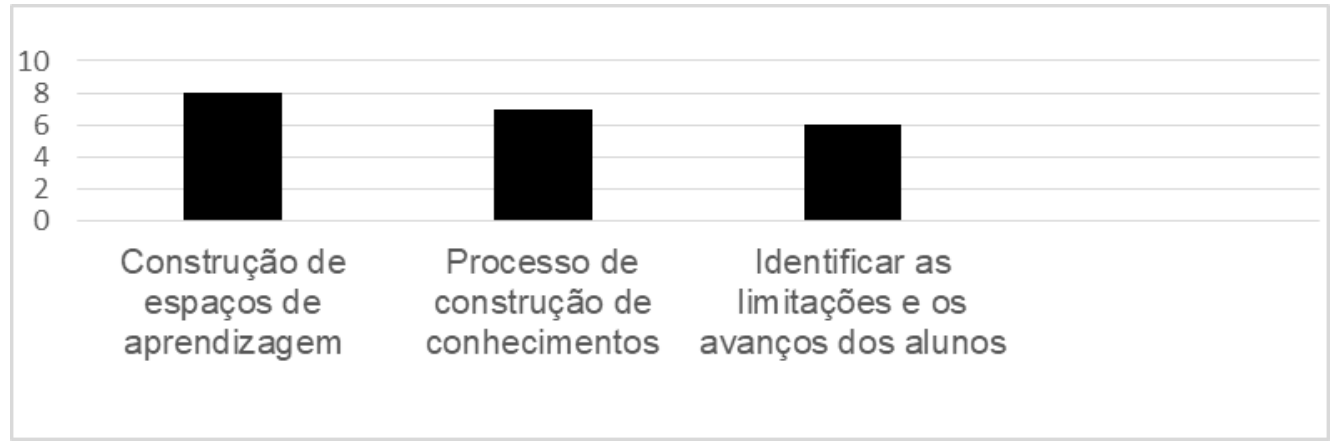

Gráfico 3 - Número de excertos presentes nas produções selecionadas que foram classificados nas subcategorias da categoria "Promoção da Aprendizagem".

Outro aspecto evidenciado no Gráfico 3 é que a maioria das pesquisas aborda a construção de outros espaços de aprendizagens, isto é, a avaliação da aprendizagem nessa perspectiva formativa "ultrapassa os muros da escola" (LEMOS; SA, 2013, p.54) como consequência de um ensino diferenciado.

A avaliação formativa, segundo Perrenoud (1999), leva o educador a observar de forma mais detalhada a trajetória de seus estudantes na tentativa de compreender melhor seus funcionamentos, ao mesmo tempo em que busca ajustes de maneira mais individualizada por meio de intervenções pedagógicas. Essa construção sugerida pelo autor de acompanhamento de forma individualizada fornece subsídios para a compreensão do processo de construção do conhecimento, bem como identifica as limitações e os avanços dos educandos.

Em relação às mudanças de concepções de avaliação, ocorrem mais facilmente quando articuladas com ações que utilizem estratégias que se aproximam de concepções construtivistas (portfólio, mapas conceituais, projetos, etc.). Isso fica evidenciado na maioria das pesquisas, como mostra o Gráfico 4, pelo fato que conduz os educadores ao exercício de reflexão crítica.



Gráfico 4 - Número de excertos presentes nas produções selecionadas que foram classificados nas subcategorias da categoria "Mudanças de concepções de avaliação". 
A utilização de estratégias de cunho construtivista pode ter relação com a intencionalidade de superar o sistema tradicional do ensino e, também, para apoiar os processos de ensino e aprendizagem, corroborando para verificar os mecanismos da cognição dos estudantes (BENEDETTI FILHO et al, 2020). Nesse sentido, essas estratégias, segundo Lorenzon (2018), podem ser consideradas pelos professores como a possibilidade de utilizar um "instrumento de avaliação flexível” para "documentar as nuances subjetivas que ocorrem cotidianamente, sem reduzi-las a uma nota ou conceito" além de contemplar "uma avaliação dos estudantes sobre os seus próprios processos de aprendizagem" (LORENZON, 2019, p.07).

Outro aspecto atrelado às mudanças de concepções dos educadores é em relação a avaliação da aprendizagem ser uma ferramenta que promove a aproximação dos professores com os estudantes por meio do diálogo, potencializando questionamentos, e a investigação a respeito do processo de aprendizagem dos estudantes.

Busca-se a aproximação e o diálogo, um olhar mais amplo, dedicado, sempre presente. É o tempo de aprender a observar, registrar, reunir dados, ler tarefas, escutar os alunos, trocar ideias com outros professores. Tempo de admirar-se com tudo o que os jovens são incrivelmente capazes de fazer (LEMOS; SÁ, 2013, p.58).

A autoavaliação surge nas pesquisas como procedimento na avaliação formativa para promover esse momento em que o educador, através dessa aproximação e do diálogo, propicia um ambiente em que o estudante analise, reflita e interprete seu percurso de aprendizagem. Nesse sentido, reportamos para o excerto retirado da pesquisa 3:

[...] a autoavaliação é uma situação de aprendizagem em que o aluno desenvolve estratégias de análise e interpretação de suas produções e dos diferentes procedimentos para se avaliar, é necessária para a construção da autonomia dos alunos e deve ser construída a partir da coordenação dos pontos de vista do aluno e do professor (AZEVEDO, 2016, p.33).

Destacamos ainda que a maioria das pesquisas selecionadas $(2,3,4,5,6,8,9$ e 10) sugerem que a reflexão crítica é o caminho para as mudanças nas concepções de avaliação. Mudanças na forma de conceber a avaliação da aprendizagem, segundo essas pesquisas, devem estar apoiadas em ações cujo processo avaliativo esteja voltado para a promoção das aprendizagens de seus educandos. 
Portanto, a avaliação que não se preocupa apenas em medir acertos e erros é pautada:

[...] em atitudes diferenciadas diante dos erros cometidos durante o processo de ensino, tendo o professor como um mediador das situações que envolvem a reconstrução de conhecimento, com feedback interativo, contínuo, estabelecendo um diálogo entre os sujeitos da educação que descambará para um redesenho das compreensões dos educandos (MARTINS, 2016, p.41).

A avaliação da aprendizagem nas pesquisas traz a compreensão que essa prática pedagógica aos poucos vai assumindo outro papel no exercício da docência e conduzindo as mudanças de concepção de avaliação. Nesse sentido, as pesquisas 8 e 10 pontuam a questão da formação do educador no sentido de se apropriar de conhecimentos, isto é, de referenciais teóricos para sustentar e viabilizar mudanças em sua práxis.

As mudanças nas concepções na maneira de avaliar as aprendizagens são referenciadas como o "tempo da reconstrução das práticas avaliativas é o tempo da ação reflexiva [...] Esse é o tempo da tomada de consciência, tempo de professores comprometidos, tempo do estudo, do preparo, da qualificação profissional (LEMOS; SÁ, 2013, p.58)”.

Por sua vez, as propostas sugeridas para o contexto escolar com intencionalidade de mudar a avaliação da aprendizagem causam grandes tensionamentos e as soluções acabam partindo de consensos entre os educadores, de forma que criam regras a fim de justificar seus atos a partir de problemas tais como infrequência, violência, disciplina e outros. E, esse fato está evidenciado em algumas pesquisas, como por exemplo, a pesquisa 10 em que os autores atribuem o termo "bricolagens" para esses arranjos que são realizados no contexto escolar.

Com relação à categoria Reorientação das práticas pedagógicas, foi possível verificar que há um entendimento que permeia a maioria das pesquisas analisadas, no sentido de uma prática de avaliação da aprendizagem com concepção formativa. O Gráfico 5 mostra a frequência dos excertos classificados na referida subcategoria.

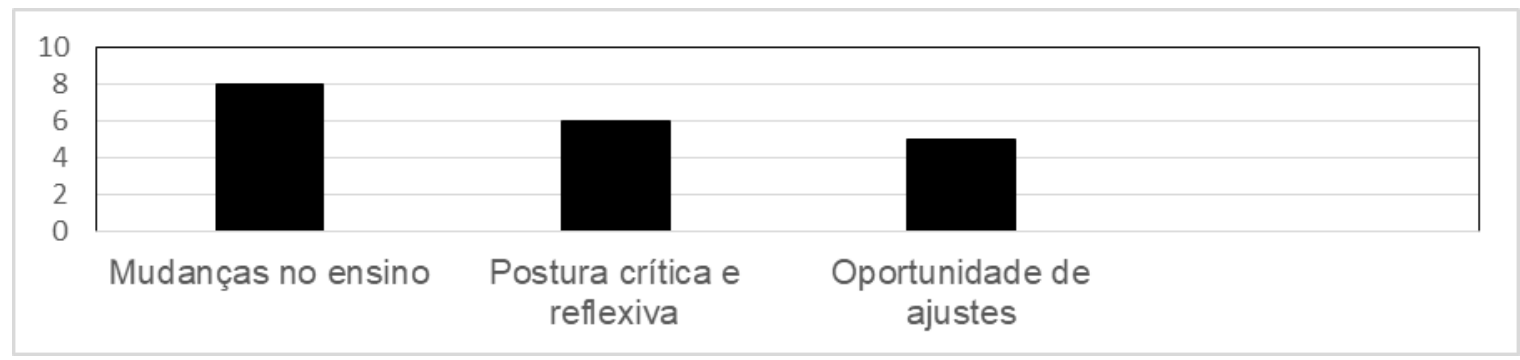


Gráfico 5 - Número de excertos presentes nas produções selecionadas que foram classificados nas subcategorias da categoria "reorientação das práticas pedagógicas".

O educador, por sua vez, ao manter uma postura crítica e reflexiva durante todo o processo avaliativo das aprendizagens dos estudantes estará contribuindo para ter um olhar investigativo para seu trabalhado docente, percebendo a necessidade de realizar ajustes cotidianos no planejamento.

Portanto, esse fato é decorrente do entendimento evidenciado nas pesquisas de que a avaliação da aprendizagem nessa construção "envolve dois componentes: avaliação para a aprendizagem (professor) e avaliação como aprendizagem (aluno) quando utilizam as informações do feedback do processo para análise e tomada de decisões (LARA; BRANDALISE, 2016, p.47)”.

A presença de excertos referentes à categoria Avaliação da aprendizagem nos projetos, foco desse estudo, surge nas pesquisas 9 e 10 e suas frequências são apresentadas no Gráfico 6. A primeira pesquisa investiga a implantação dessa metodologia em duas escolas públicas municipais da região metropolitana de Porto Alegre - RS, com a finalidade de verificar a influência da PP no processo avaliativo; e a segunda utiliza a proposta de Ensino por Projetos de Fernando Hernández e Montserrat Ventura (1998) em três escolas públicas municipais de Porto Alegre - RS, como intervenção junto a educadores do ensino de Física para obter proximidade com a perspectiva da avaliação formativa.

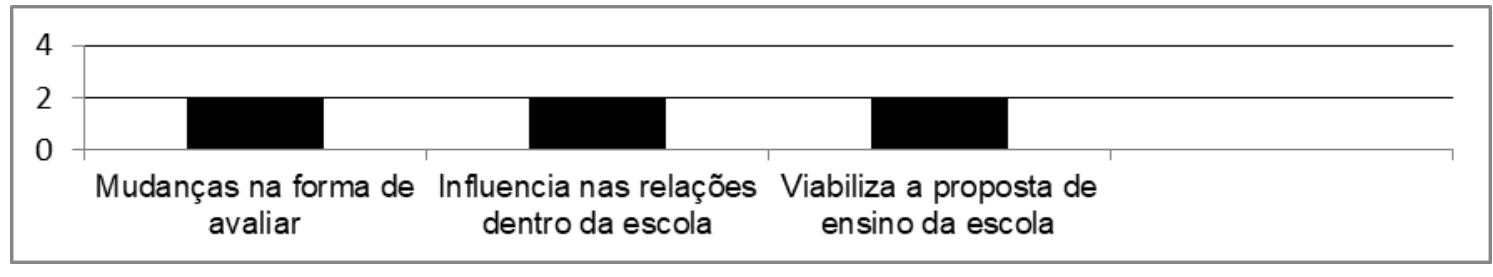

Gráfico 6 - Número de excertos presentes nas produções 9 e 10 classificados nas subcategorias da categoria "Avaliação da aprendizagem dos projetos"

O entendimento de que os professores, nessa proposta pedagógica, atuam no sentido que devem "criar situações de aprendizagem" que garantam "a compreensão dos conceitos utilizados” (PRASNISKI, 2015. p.37) está presente nas duas pesquisas. Nessa perspectiva, Perrenoud (1999) alerta que as pedagogias ativas e interativas, ao proporem diferenciadas 
situações de aprendizagem e outras formas de organização dos educandos, exigirá mudanças em relação à maneira de avaliar as aprendizagens.

Ainda para Perrenoud (1999), poderão surgir situações de medo por parte dos educadores por não poderem mais avaliar da maneira convencional. A pesquisa 9 evidencia que uma das escolas, mesmo trabalhando todo ano com projetos como estratégias extracurriculares, ainda utiliza avaliações pontuais, como a prova, para verificar as aprendizagens.

A pesquisa 9 expressa que em uma das escolas as mudanças na organização escolar decorrentes da adoção da PP, inicialmente gerou muita resistência por parte dos educadores. Esse fato decorreu, segundo os pesquisadores, em virtude da exigência de novas formas de organizar a prática docente, bem como de planejar e de avaliar os alunos, de maneira a acompanhar o desenvolvimento da aprendizagem em uma perspectiva contínua e formativa.

Segundo Perrenoud (1999, p.16), argumenta-se que a avaliação formativa e as pedagogias diferenciadas esbarram geralmente com inúmeros obstáculos materiais e institucionais. O autor cita, por exemplo, "o efetivo das turmas, a sobrecarga dos programas e a concepção dos meios de ensino e das didáticas, que quase não privilegiam a diferenciação".

Contudo, em ambas as pesquisas 9 e 10, a Pedagogia do Projetos leva a refletir também sobre as relações estabelecidas dentro da escola com seus pares e demais sujeitos, podendo viabilizar novas formas de pensar o ensino e o processo de aprendizagem dos educandos.

\section{CONSIDERAÇÕES FINAIS}

A proposta do artigo em debruçar-se sobre as produções científicas nos repositórios da CAPES - MEC e LUME - UFRGS para mapear as concepções de avaliação da aprendizagem no ensino das Ciências da Natureza por meio da PP é pertinente para o momento atual em que os sistemas de ensino de todo o país estão envolvidos por grandes mudanças na Educação Básica. As mudanças, por exemplo, conduzem a adequação das escolas com a Base Nacional Comum Curricular (BNCC), o Novo Ensino Médio, a Educação em Tempo Integral e as novas diretrizes para o Ensino Fundamental.

À medida que as mudanças vão se estabelecendo nos contextos escolares, novas orientações tentam mobilizar os educadores a investirem em outras formas de ensinar. 
Principalmente, no sentido de utilizar metodologias diferenciadas onde o estudante não atue como um mero espectador, mas que exijam participação, atuação, comprometimento com seu processo educativo e articulação com experiências vivenciadas em seus cotidianos.

No entanto, o que as pesquisas revelam é que têm sido muito difícil para os educadores adotarem outras formas de ensinar, muito embora percebam que o ensino como está sendo propagado no cotidiano de sala de aula não atende às necessidades dos estudantes, principalmente no que tange ao processo de aprendizagem e a integralidade do ser.

A inovação do ensino através de metodologias ativas requer pensar em todo ato pedagógico, com enfoque na avaliação da aprendizagem para que possa potencializar o tipo ensino que se pretende. Nesse sentido, as impressões que perpassam as produções científicas são de uma avaliação da aprendizagem com função formativa em que reside a intencionalidade de avaliar para compreender e explicar o processo de aprendizagem e a mudança do papel do educador.

O aporte teórico presente nas produções científicas remete a uma concepção que se aproxima do construtivismo e com uma avaliação da aprendizagem a qual deve ser processual, dialógica, diagnóstica, mediadora, formativa e integrada aos processos de ensino e de aprendizagem. Por outro lado, os pesquisadores nos conduzem a pensar que, apesar dos documentos oficiais direcionarem para um discurso de avaliação formativa, a concepção de avaliação somativa ainda está muito presente nas escolas como uma prática classificatória e excludente.

A presente pesquisa evidencia que no contexto atual é necessário mudanças na forma de avaliar as aprendizagens, principalmente, quando os educadores propõem incorporar em seu trabalho docente estratégias na concepção construtivista. Essas estratégias preveem a participação ativa de educadores e educandos no processo de construção do conhecimento e, nessa lógica podem conduzir a um caminho de reflexão crítica.

Surge, então, uma inquietação: Como avaliar as aprendizagens dentro do ensino por meio de Projetos realizados no Ensino de Ciências diante dessa realidade?

A inquietação surge por se tratar de uma concepção de educação na qual, segundo Hernandez e Ventura (1998), o educador precisa sair de sua zona de conforto para exercer um 
papel de mediador no desenvolvimento das atividades dentro dos projetos em um ambiente de aprendizagem colaborativo. O desenvolvimento de projetos relacionados a temáticas de interesses dos estudantes provoca a aproximação com seus projetos de vida e questões ligadas a realidade. Portanto, exige romper com concepções de uma avaliação tradicional e classificatória.

Dessa forma, os elementos que são apontados neste artigo a partir da revisão sistemática de literatura em produções científicas, conduzem a pensar que a avaliação da aprendizagem nos projetos requer concepções que precisam estar relacionadas com uma perspectiva formativa, rompendo com a concepção classificatória no sentido de promover a aprendizagem.

Mas, para que essa construção ocorra se faz necessário que os educadores, em especial aos que trabalham com Projetos, se rendam ao exercício da reflexão crítica, busquem subsídios teóricos e realizem práticas avaliativas mais humanizadas.

\section{REFERÊNCIAS}

ARAÚJO, U. Temas transversais, pedagogia de projetos e mudanças da educação. São Paulo: Summus Editorial, 2014;

AZEVEDO, A.V. Avaliação: uma proposta de orientação da aprendizagem do aluno e reorientação da prática pedagógica do professor. Dissertação (Mestrado em Ensino de Ciências e Matemática) 2016. 94f. Universidade Federal de Pelotas, Pelotas, 2016.

BARDIN, L. Análise de conteúdo. Lisboa: Edições 70, 2016;

BENEDETTI, L. et al. Uso de um mapa conceitual adaptado envolvendo atividades lúdicas para o ensino de Química. Revista Insignare Scientia - RIS, Cerro Largo, v. 3, n. 2, p. 220-236, 24 ago. 2020.

DANTAS, C.R.S. Avaliação no ensino de ciências no nível fundamental: investigando orientações oficiais e práticas docentes, fazendo "escuta" e intervenções em escolas. 2017. 443f. Tese (Doutorado em Ensino de Física). Universidade Federal do Rio Grande do Sul, Porto Alegre, 2017.

ESTEBAN, M.T. Pedagogia de projetos: entrelaçando o ensinar, o aprender e o avaliar à democratização do cotidiano escolar. Porto Alegre: Mediação, 2012; 
GALVÃO, E.C.; SOUZA, N.A. O compromisso formativo na avaliação da aprendizagem em Química. Revista Roteiro, Joaçaba, v. 41, n. 2, p. 379-406, maio/ago. 2016.

GIL, A. C. Como Elaborar Projetos de Pesquisa. 4a ed. São Paulo: Atlas, 2002;

HERNANDEZ, F.; VENTURA, A. Organização do Currículo por Projetos de Trabalho: O Conhecimento é um Caleidoscópio. Porto Alegre: Artmed, 1998;

KITCHENHAM, B. (2004). Procedures for performing systematic reviews. Keele, UK, Keele University, 33(TR/SE-0401), 28, 2004.

LARA, V.A.; BRANDALISE, M.A.T. (2016) Avaliação da Aprendizagem na escola organizada em ciclos: concepções dos professores. Fundação Carlos Chagas, São Paulo, v. 27 n.64, p.36-68, jan./abr. 2016.

LEMOS, P.S.; SA, L.P. A avaliação da aprendizagem na concepção de professores de Química do Ensino Médio. Revista Ensino e Pesquisa em Educação em Ciências, Belo Horizonte, v.15, n.3, p.53-71. 2013.

LIMA, J.A.; SAMPAIO C.G.; BARROSO, M.C.S.; VASCONCELOS, A.K.P. Avaliação da aprendizagem em Química com uso de mapas conceituais. Revista Thema, Pelotas, v.14, n.2, p. 37-49. 2017.

LORENZON, M. Os Portfólios como instrumento avaliativo em uma proposta de Ensino por Investigação. Revista Insignare Scientia - RIS, Cerro Largo, v. 1, n.3. 17 fev. 2019.

LÜDKE, M. O trabalho com projetos e a avaliação na educação básica. Porto Alegre: Mediação, 2012.;

MARTINS, A. A. Concepções de um grupo de professores de Ciências da Natureza e suas Tecnologias sobre o ensino por pesquisa e sobre avaliação aplicada a essa perspectiva de ensino: encontros e desencontros em torno dessa práxis. 2016. 91f. Dissertação (Mestrado em Educação em Ciências: Química da Vida e da Saúde). Universidade Federal do Rio Grande do Sul, Porto Alegre, 2016.

MOSÉ, V. A escola e os desafios contemporâneos. Rio de Janeiro: Civilização Brasileira, 2013;

NASCIMENTO, L.P.; ROÇAS, G. Portfólio: uma opção de avaliação integrada para o ensino de Ciências.

PRASNISKI, M. E. T. (2015) Avaliação no ensino de ciências: estudo na implantação da pedagogia de projetos em escola pública de ensino básico da região metropolitana de Porto Alegre. 2015. 119f. Dissertação (Mestrado em Educação em Ciências e Matemática). Pontifícia Universidade Católica do Rio Grande do Sul, Porto Alegre, 2015. 
PERRENOUD, P. Avaliação: da excelência à regulação das aprendizagens - entre duas lógicas. Porto Alegre: Artes Médicas, 1999;

SILVA, F.C. Proposta de avaliação formativa aplicando a aprendizagem baseada em problemas (ABP) no Ensino Médio. 2017. 78f. Dissertação (Mestrado em Ciências). Universidade de São Paulo, Lorena, 2017.

SCHAFF, A. A sociedade informática. São Paulo: Universidade Paulista, Editora Brasiliense, 1995;

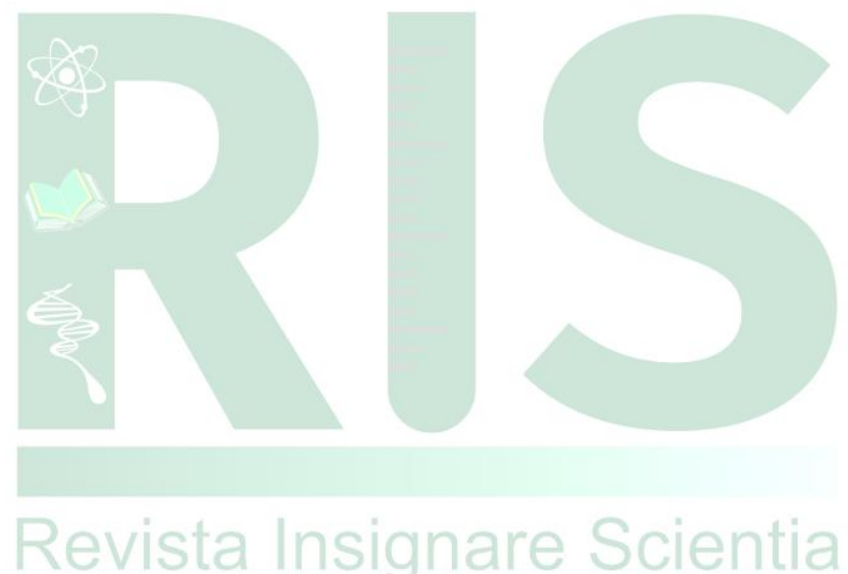

